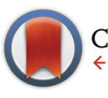

CrossMark $\leftarrow$ click for updates

Cite this: Dalton Trans., 2016, 45 15840

Received 29th March 2016,

Accepted 29th April 2016

DOI: 10.1039/c6dt01208f

www.rsc.org/dalton

\section{Iron(II) $\beta$-ketiminate complexes as mediators of controlled radical polymerisation $\uparrow$}

\begin{abstract}
Benjamin R. M. Lake and Michael P. Shaver*
A series of tridentate, $\mathrm{ONO}$ - and $\mathrm{ONN}$-chelating $\beta$-ketiminate ligands were synthesised via condensation reactions, and complexed with iron(॥) using $\left[\mathrm{Fe}\left(\mathrm{N}\left(\mathrm{SiMe}_{3}\right)_{2}\right)_{2} \mathrm{THF}\right]$. The complexation reactions proceeded in high yields to generate novel, monomeric, tetracoordinate iron(॥) complexes, each bearing a bis(trimethylsilyl)amide ligand, as confirmed by X-ray crystallography. These complexes were amenable to further reaction (protonolysis) with alcohols and phenols, generating alkoxide/phenolate-containing complexes that were dimeric in the solid state. All complexes synthesised were screened as potential mediators of the controlled radical polymerisation (CRP) of styrene and methyl methacrylate under both atom transfer radical polymerisation (ATRP) and organometallic mediated radical polymerisation (OMRP) conditions. Whilst all of the complexes were relatively poor ATRP mediators under the conditions used here, regardless of monomer choice, dispersities $(\Theta)$ as low as 1.58 for styrene and 1.23 for methyl methacylate polymerisation under OMRP conditions could be achieved. The better performance in methacrylate polymerisation suggests the formation of a stronger metal-carbon bond in these systems. In particular, the use of a $\beta$-ketiminate ligand functionalised with an $N, N$-dimethylethylene pendant arm and a 2,6-diphenylphenolate ligand affords a potential Fe-based mediator of methyl methacrylate OMRP.
\end{abstract}

\section{Introduction}

The application of iron compounds as catalysts in organic chemistry is a vibrant area of research. ${ }^{1}$ This is due, in part, to the low cost of iron, its high crustal abundance, and its biocompatibility. Furthermore, the ability of iron to adopt a range of oxidation states $(-2$ to +5$)$ and spin-states allows it to display remarkably variable reactivity, thus allowing it to participate in a wide range of chemical reactions. Indeed, soon after the pioneering initial reports by the groups of Matyjaszewski $^{2}$ and Sawamoto ${ }^{3}$ on the controlled radical polymerisation (CRP) of alkene monomers, the first reports of the use of iron complexes as mediators of this important reaction began to appear. ${ }^{4}$ The use of iron complexes as mediators of CRP has now grown so considerably, that a number of reviews covering this thriving field have been recently published. ${ }^{5}$

As part of our continuing studies on utilising new ironbased mediators for $\mathrm{CRP}^{6}$ and understanding the underlying mechanisms by which these complexes impart control over

EaStCHEM School of Chemistry, University of Edinburgh, Edinburgh, EH9 3FJ, UK. E-mail: michael.shaver@ed.ac.uk

$\dagger$ Electronic supplementary information (ESI) available: GPC data, ${ }^{1} \mathrm{H}$ NMR spectra and single crystal X-ray diffraction data. CCDC 1470307-1470310, 1470323, 1470324 and 1470383-1470385. For ESI and crystallographic data in CIF or other electronic format see DOI: 10.1039/c6dt01208f polymerisation reactions, ${ }^{7}$ we sought to develop a new series of iron complexes based on the $\beta$-ketiminate ligand scaffold. Iron- $\beta$-ketiminate complexes have been scarcely used as mediators of CRP, ${ }^{5 a, c}$ with only one report to the best of our knowledge published to date. ${ }^{8}$ We specifically chose $\beta$-ketiminates to support our iron complexes, due to the ease with which these ligands are synthesised and the inexpensive starting materials required to make them, both of which would be especially attractive features for use at production scale. ${ }^{9}$ Furthermore, the electronic and steric characteristics can be controlled by tuning the $\beta$-ketiminate scaffold, including through the introduction of additional donors. This ability to shape the coordination sphere could be especially important as we pursue systems that can reversibly trap radicals via the formation of a new metal-carbon bond.

In this report, we detail the synthesis of $\alpha, \beta$-unsaturated$\beta$-ketoamines bearing pendant amine, ether and pyridyl donors. The reaction of these compounds with the iron-containing precursor $\left[\mathrm{Fe}\left(\mathrm{N}\left(\mathrm{SiMe}_{3}\right)_{2}\right)_{2} \mathrm{THF}\right]$ produced a series of four-coordinate complexes, with bound bis(trimethylsilyl) amide donors. A second family of catalysts was generated through protonolysis of these compounds with benzyl alcohol or 2,6-diphenylphenol, yielding dimeric (in the solid state) iron(II) complexes bearing alkoxide or phenolate ligands. All of the iron complexes synthesised were examined as mediators of CRP under both atom transfer radical polymerisation (ATRP, 
alkyl halide initiator) and organometallic mediated radical polymerisation (OMRP, azo initiator) conditions.

By using iron(II) rather than the more stable iron(III) complexes, we are able to separate out the halogen and organometallic mechanisms and draw conclusions about the role of both ATRP and OMRP equilibria (vide infra) in imparting control over the polymerisation reactions described herein. The information gained during the course of these studies is additionally of potential relevance to all metal mediated CRP reactions, and is helping to guide our development of effective iron-based mediators.

\section{Results and discussion}

\section{Synthesis and characterisation}

The synthesis of $\alpha, \beta$-unsaturated- $\beta$-ketoamines, precursors to $\beta$-ketiminates, bearing pendant donor functionalities was achieved via the condensation of acetylacetone and the appropriate primary amine at reflux (Scheme 1). Contrary to previously published reports, ${ }^{10}$ we found that the reactions proceeded efficiently in methanol without the need for an acid catalyst. The ligand precursors $\mathbf{L 1 H}$ and $\mathbf{L} \mathbf{2 H}$ were obtained as pale yellow oils following purification by vacuum distillation, while $\mathbf{L} 3 \mathbf{H}$ and $\mathbf{L} \mathbf{H}$ H could be obtained as colourless crystalline solids by recrystallisation. All four $\alpha, \beta$-unsaturated- $\beta$-ketoamines display broad singlet resonances between 10.77-11.26 ppm $\left(\mathrm{CDCl}_{3}\right)$, characteristic of the hydrogen-bonded amine proton. ${ }^{11}$ Ligand precursors $\mathbf{L 3 H}$ and $\mathbf{L 4 H}$ also each show a doublet resonance $(J \approx 6.5 \mathrm{~Hz})$ at 4.57 and $4.52 \mathrm{ppm}\left(\mathrm{CDCl}_{3}\right)$, respectively, corresponding to the picolyl- $\mathrm{CH}_{2}$ protons coupling to the amine proton.

Previous publications have reported the synthesis of transition metal complexes bearing donor-tethered $\beta$-ketiminates using various strategies, including by reaction of the ligand precursor and metal salt in the presence of a base ${ }^{10 a}$ and without a base, ${ }^{12}$ by reaction of the ligand precursor with a highly basic metal starting reagent ${ }^{13}$ and by transmetalation from an alkali metal- $\beta$-ketiminate complex. ${ }^{10 c, 14}$ We decided to use a simple strategy and form our desired $\mathrm{Fe}^{\mathrm{II}}(\mathrm{L})\left(\mathrm{N}\left(\mathrm{SiMe}_{3}\right)_{2}\right)$ type complexes in a one-pot reaction using $\left[\mathrm{Fe}\left(\mathrm{N}\left(\mathrm{SiMe}_{3}\right)_{2}\right)_{2} \mathrm{THF}\right]$ as the basic metalating reagent. Indeed, reaction of the $\alpha, \beta$-unsaturated- $\beta$-ketoamines, $\mathbf{L 1 H}-\mathbf{L 4 H}$, with an equimolar amount of $\left[\mathrm{Fe}\left(\mathrm{N}\left(\mathrm{SiMe}_{3}\right)_{2}\right)_{2} \mathrm{THF}\right]$ in hexane or toluene led to the formation of green-yellow solutions/suspensions, from which, highly oxygen and moisture-sensitive solids could be obtained upon work-up (Scheme 2). The products (1a-4a) were obtained in good yields $(>72 \%)$ and isolated as green crystalline solids. Characterisation of $\mathbf{1 a - 4 a}$ by ${ }^{1} \mathrm{H}$ NMR spectroscopy revealed paramagnetically-shifted spectra, with a series of broad resonances between approximately -60 and $180 \mathrm{ppm}$ present in each spectrum (see ESI $\dagger$ ). The solution magnetic moments of these complexes were suggestive of $\mathrm{d}^{6}$ high-spin electron configurations at ambient temperature, with calculated values (4.9-5.4 $\left.\mu_{\mathrm{B}}\right)$ congruent with the spin-only magnetic moment of a high-spin iron(II) centre $\left(4.90 \mu_{\mathrm{B}}\right)$. Single crystals of all four complexes (1a-4a) suitable for X-ray diffraction analysis could be obtained, either directly from the bulk material, or by cooling a saturated $n$-hexane solution of the product to $-35{ }^{\circ} \mathrm{C}$. The molecular structures of complexes $1 \mathbf{a}-\mathbf{4 a}$ are provided in Fig. 1 and 2 along with selected bond lengths and angles. All four complexes have crystallised as monomeric, four-coordinate species, with the coordination sphere of each comprising the N,O-donors of the $\beta$-ketiminate backbone, the heteroatom of the tethered donor and the $\mathrm{N}$ atom of a bis(trimethylsilyl)amide. The coordination geometries about all four iron(II) centres (1a-4a) can be described as distorted seesaw according to the four-coordinate geometry index proposed by Houser in the pages of this journal, ${ }^{15}$ with $\tau_{4}$ values of 0.60 , $0.56,0.57$ and 0.54 respectively. The coordination geometries can alternatively be described using Alvarez's system, ${ }^{16}$ which suggests a tendency towards an intermediate (spread) geometry. This geometry is extremely rare indeed for $\mathrm{d}^{6}$ metal ions, ${ }^{16 a}$ and it is likely that the unusual coordination geometry is imposed by a combination of the conformational requirements of the relatively rigid tridentate $\beta$-ketiminate ligand, and the extreme steric bulk imparted by the bis(trimethylsilyl) amide donor. The bond metrics of $\mathbf{1 a - 4 a}$ are comparable to those of the iron(II)- $\beta$-ketiminates (though most of these are iron(II)-bis- $\beta$-ketiminate complexes) reported in the literature so far, ${ }^{8,11,17}$ with $\mathrm{O}_{\text {ketiminate }}$-Fe bond lengths of $1.96 \AA$ and $\mathrm{N}_{\text {ketiminate }}-\mathrm{Fe}$ bond lengths of between 2.04-2.06 $\AA$. The $\mathrm{N}_{\text {hmds }}-$ Fe bond lengths of 1.95-1.96 $\AA$ are slightly longer than those of the three-coordinate starting material (1.92 $\AA$ ), $\left[\mathrm{Fe}\left(\mathrm{N}\left(\mathrm{SiMe}_{3}\right)_{2}\right)_{2} \mathrm{THF}\right],{ }^{18}$ but compare reasonably well with the $\mathrm{N}_{\text {hmds }}-\mathrm{Fe}^{\mathrm{II}}$ bond lengths in other reported four-coordinate complexes containing a coordinated bis(trimethylsilyl)amide. ${ }^{19}$

The bis(trimethylsilyl)amide-containing complexes $\mathbf{1 a}$ and 3a were amenable to protonolysis reactions (complexes $\mathbf{2 a}$ and

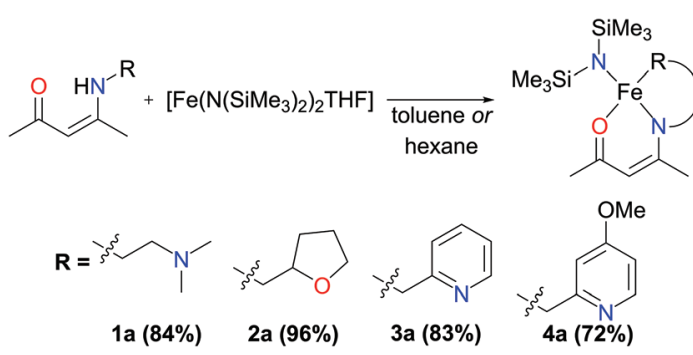

Scheme 2 Synthesis of $1 a-4 a$. 


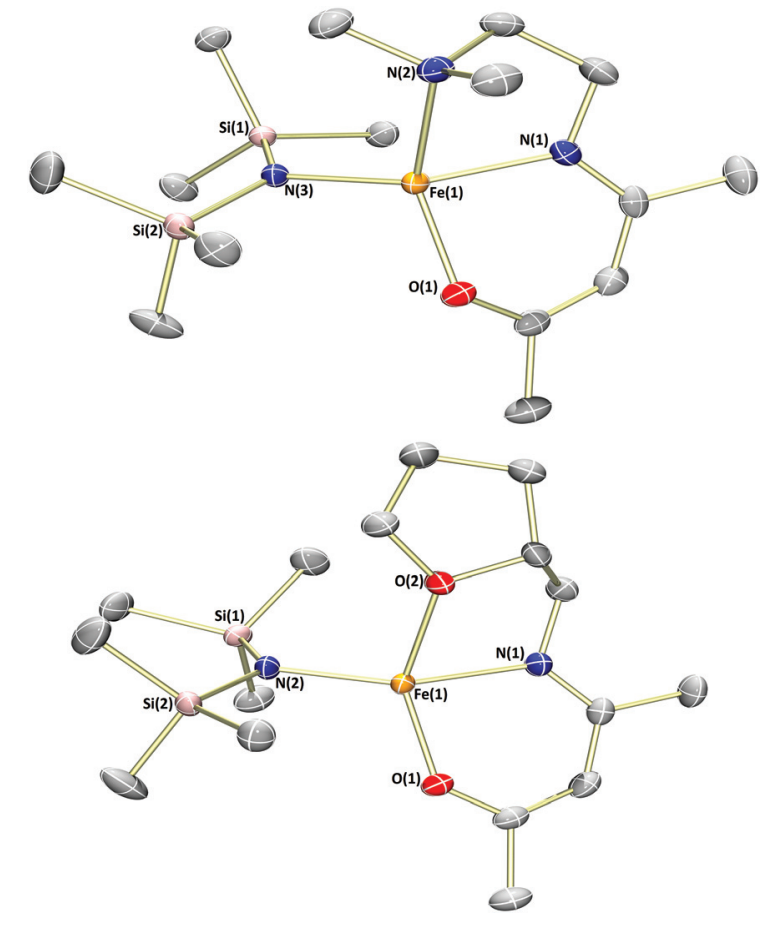

Fig. 1 Molecular structures of 1a (top) and 2a (bottom) with ellipsoids set at the $50 \%$ probability level. Hydrogen atoms have been omitted for clarity. Selected bond lengths (Å) and angles $\left({ }^{\circ}\right)$ : 1a - Fe1-O1 1.9601(11), Fe1-N1 2.0409(13), Fe1-N2 2.2342(13), Fe1-N3 1.9596(13), O1-Fe1-N2 134.54(5), O1-Fe1-N1 90.24(5), N3-Fe1-O1 110.48(5), N3-Fe1-N2 105.08(5), N3-Fe1-N1 140.40(5), N1-Fe1-N2 79.40(5). 2a - Fe1-O1 1.9614(9), Fe1-N1 2.0559(10), Fe1-O2 2.1418(9), Fe1-N2 1.9472(9), O1Fe1-O2 133.40(4), O1-Fe1-N1 89.56(4), N1-Fe1-O2 76.66(4), N2-Fe1$\mathrm{O} 1$ 113.98(4), N2-Fe1-O2 98.99(4), N2-Fe1-N1 148.22(4).

4a were not examined). Reaction of either of these two complexes with a hexane solution of benzyl alcohol led to an immediate and distinct colour change from green-yellow to red or orange. After a simple work-up, the products $\mathbf{1 b}$ and $\mathbf{3 b}$ were isolated as orange and red solids respectively (Scheme 3).

Analysis of the products by ${ }^{1} \mathrm{H}$ NMR spectroscopy again revealed a series of paramagnetically-shifted resonances, with solution magnetic moment data $\left(\mu_{\mathrm{eff}}=5.4\right.$ and $5.2 \mu_{\mathrm{B}}$, respectively) indicative of $\mathrm{d}^{6}$ high-spin electron configurations. Single crystals of complex $\mathbf{1 b}$ suitable for X-ray diffraction analysis were obtained on cooling of a saturated $n$-hexane solution from reflux (Fig. 3). The solid-state structure of $\mathbf{1 b}$ reveals a dimer, with $\left(\mu^{2}-\mathrm{OBn}\right)_{2}$ bridging the two iron(II) centres. The two halves of the dimer are related to each other through a crystallographic inversion centre, located in the centre of the $\mathrm{Fe}_{2} \mathrm{O}_{2}$ rhombus, with each five-coordinate iron(II) possessing a coordination geometry best described as square pyramidal. Single crystals of complex $\mathbf{3} \mathbf{b}$, obtained from a dilute toluene/ $n$-hexane solution stored at $-35^{\circ} \mathrm{C}$, show that this complex is isostructural with $\mathbf{1 b}$.

As an electronic and steric contrast between the bulky amide-containing complexes $\mathbf{1 a}-\mathbf{4 a}$, and the relatively nonbulky alkoxide-containing complexes $\mathbf{1 b}$ and $\mathbf{3 b}$, we decided to synthesise bulky phenoxide-containing complexes of iron(II)

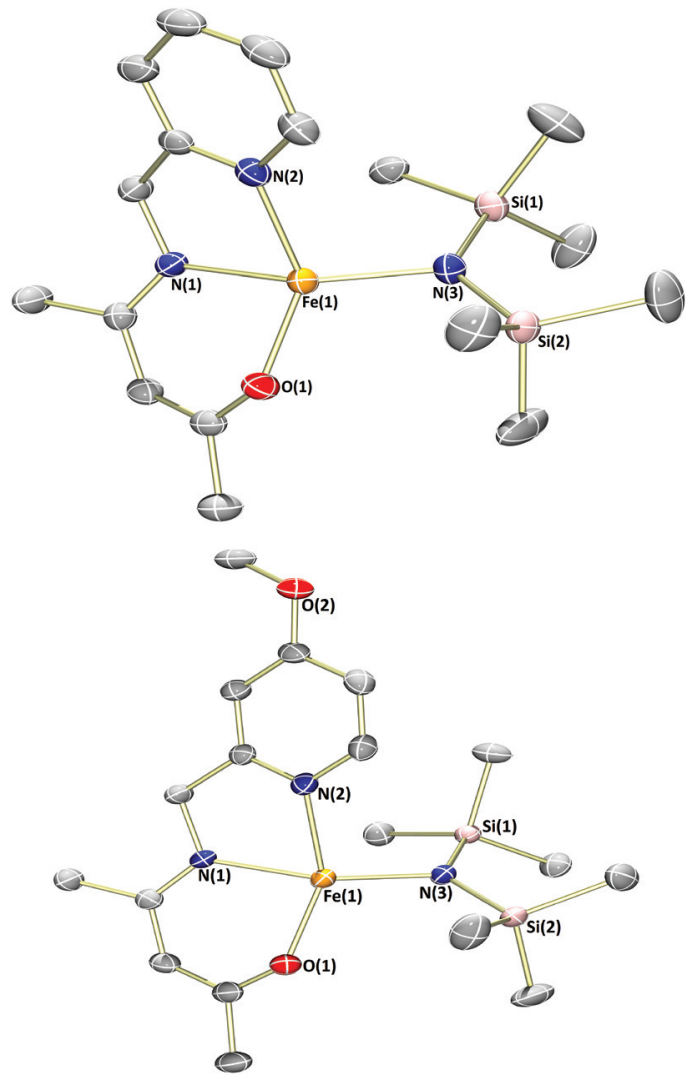

Fig. 2 Molecular structures of 3a (top) and 4a (bottom) with ellipsoids set at the $50 \%$ probability level. Hydrogen atoms have been omitted for clarity. Selected bond lengths $(\AA \AA)$ and angles $\left({ }^{\circ}\right)$ : 3a - Fe1-O1 1.9599(14), Fe1-N1 2.0598(16), Fe1-N2 2.1443(17), Fe1-N3 1.9574(17), O1-Fe1-N1 88.95(6), O1-Fe1-N2 132.28(6), N1-Fe1-N2 77.67(7), N3-Fe1-O1 112.75(7), N3-Fe1-N1 147.36(7), N3-Fe1-N2 101.77(7). 4a - Fe1-O1 1.9638(13), Fe1-N1 2.0601(14), Fe1-N2 2.1430(16), Fe1-N3 1.9547(14), O1-Fe1-N1 89.02(6), O1-Fe1-N2 140.71(6), N1-Fe1-N2 77.97(6), N3Fe1-O1 111.83(6), N3-Fe1-N1 143.53(6), N3-Fe1-N2 99.82(6).

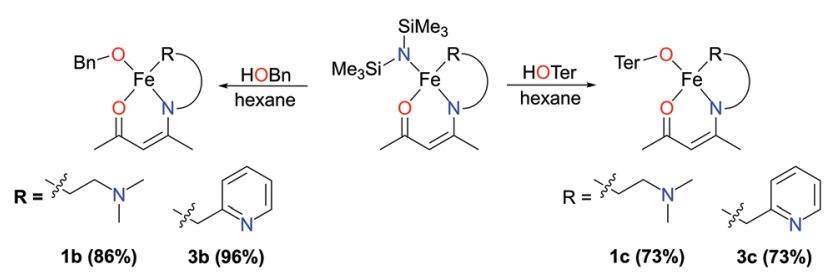

Scheme 3 Synthesis of complexes $1 b, 3 b, 1 c$ and $3 c$.

bearing our tridentate $\beta$-ketiminate ligands. Terphenolate was chosen in this case, as it has been shown to support iron in the +2 and +3 oxidation states and in a number of different coordination geometries. ${ }^{20}$ Furthermore, it has been shown that the steric bulk provided by terphenolate ligands can enhance reactivity by protecting a coordination site at the metal centre. ${ }^{21}$ Similarly to the synthesis of benzyl alkoxidesubstituted complexes $\mathbf{1 b}$ and $\mathbf{3 b}$, reaction of parent complexes 1a and 3a with 2,6-diphenylphenol (HOTer) led to immediate colour changes, and isolation of yellow/orange solids following 

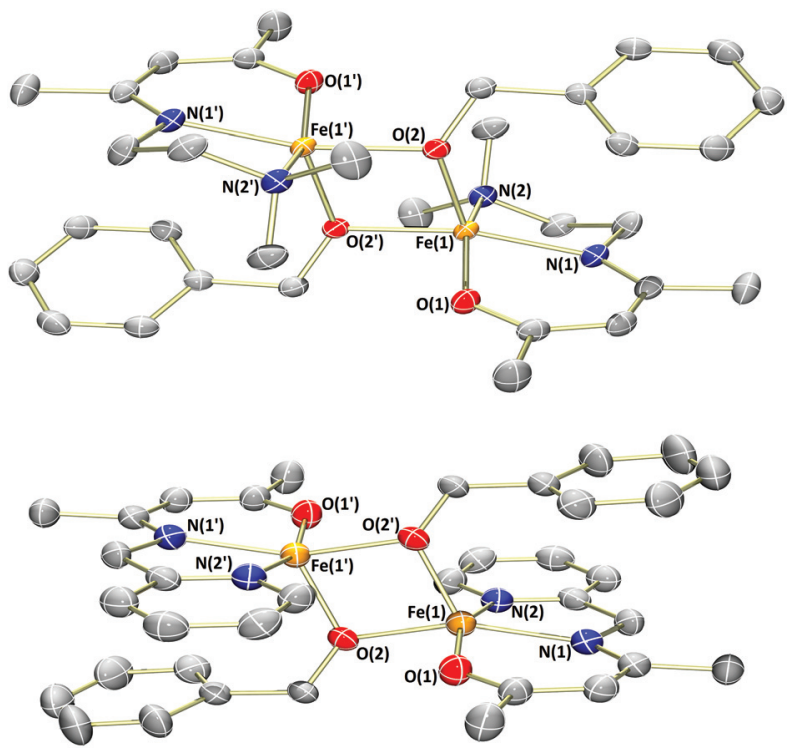

Fig. 3 Molecular structures of $\mathbf{1 b}$ (top) and $3 \mathrm{~b}$ (bottom) with ellipsoids set at the $50 \%$ probability level. Hydrogen atoms have been omitted for clarity. Selected bond lengths (Å): 1b - Fe1-O1 2.0223(10), Fe1-O2 2.0354(9), Fe1-O2' 2.0436(9), Fe1-N1 2.0908(12), Fe1-N2 2.2864(12). 3b - Fe1-O1 1.994(4), Fe1-O2 2.047(4), Fe1-O2' 2.061(4), Fe1-N1 2.102(4), Fe1-N2 2.171(5).

work-up (Scheme 3). The terphenolate-substituted complexes 1c and $3 \mathbf{c}$ were obtained in good yields $(73 \%)$, and could be fully characterised, including by single crystal X-ray diffraction analysis (Fig. 4). The solid-state structure of 1c again reveals a dimer, with the crystallographic asymmetric unit containing two structurally similar molecules of dimer and two molecules of solvent (see ESI $\dagger$ ), though both the solvent and one dimer have been omitted for clarity's sake in Fig. 4. Complex 1c contains iron(II) centres bridged by the two oxygen atoms of the two substituted $\beta$-ketiminates, with the terphenolate ligands bound in a terminal fashion. The central $\mathrm{Fe}_{2} \mathrm{O}_{2}$ rhombus of both dimers is noticeably puckered, while those of complexes $\mathbf{1 b}$ and $\mathbf{3 b}$ are planar, which presumably helps alleviate steric clashing between adjacent terphenolate aromatic rings. The four iron(II) centres contained within the two dimers of the asymmetric unit possess a range of coordination geometries, from slightly distorted square pyramidal to intermediate. Given the bridging nature of the $\beta$-ketiminate oxygen atoms, it is not surprising that the $\mathrm{O}_{\text {ketiminate }}-\mathrm{Fe}$ bond distances are typically somewhat longer than those found in either $\mathbf{1 a}$ or $\mathbf{1} \mathbf{b}$, with lengths of between 2.05-2.18 ̊. In contrast to 1c, the two iron(II) centres of complex $3 \mathbf{c}$ are bridged by an oxygen atom of one of the $\beta$-ketiminates and an oxygen atom of one of the terphenolates. The reason for this bridging mode is somewhat unclear, though maximising intramolecular $\pi-\pi$ stacking interactions between the terphenolate and pyridyl rings could be a contributory factor.

\section{Controlled radical polymerisation}

The two main equilibria by which metal-mediated CRP proceeds are ATRP and OMRP (Scheme 4). ${ }^{22}$ ATRP involves the

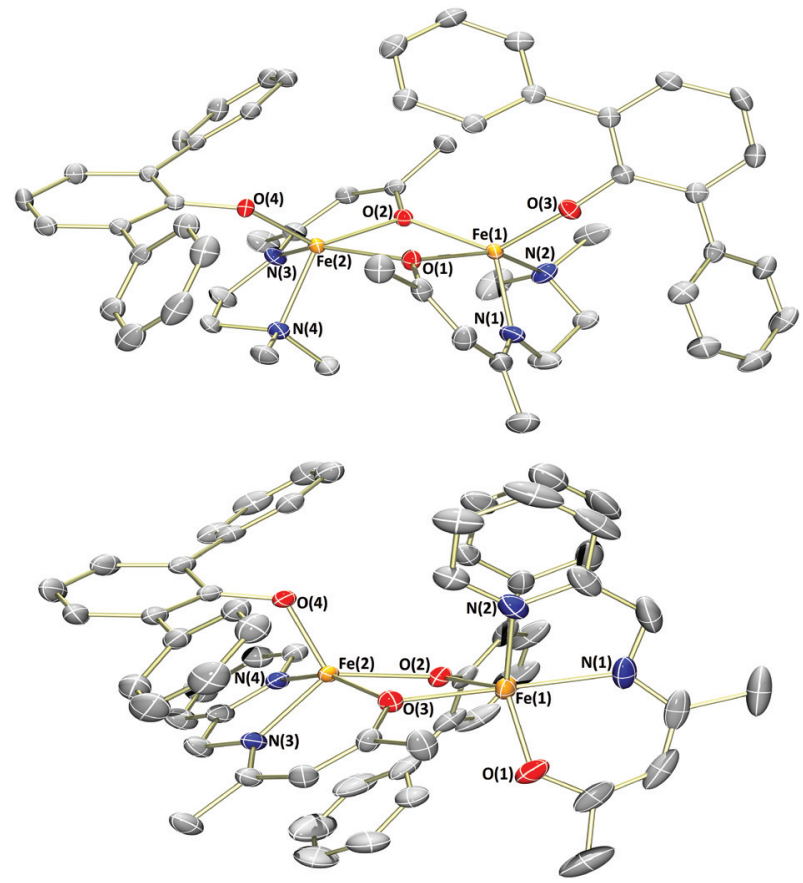

Fig. 4 Molecular structures of 1c (top) and 3c (bottom) with ellipsoids set at the $50 \%$ probability level. Hydrogen atoms and co-crystallised solvent have been omitted for clarity. Selected bond lengths (Å): 1c - Fe1-O1 2.097(2), Fe1-O2 2.100(2), Fe1-O3 1.894(2), Fe1-N1 2.109(3), Fe1-N2 2.248(3), Fe2-O1 2.176(2), Fe2-O2 2.049(2), Fe2-O4 1.942(2), Fe2-N3 2.126(3), Fe2-N4 2.228(3). 3c - Fe1-O1 1.985(2), Fe1$\mathrm{O} 2$ 2.045(2), Fe1-O3 2.120(2), Fe1-N1 2.084(3), Fe1-N2 2.133(3), $\mathrm{Fe} 2-\mathrm{O} 2$ 2.107(2), Fe2-O3 2.077(2), Fe2-O4 1.970(2), Fe2-N3 2.080(3), $\mathrm{Fe} 2-\mathrm{N} 4$ 2.154(3).

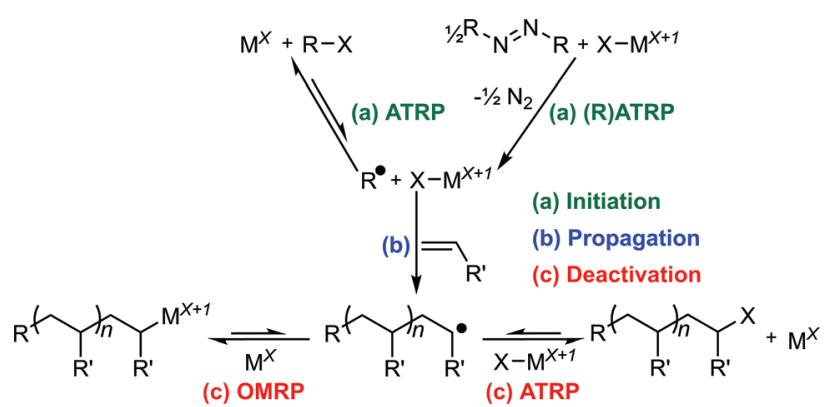

Scheme 4 Equilibria implicated in CRP. ${ }^{6 b}$

reversible transfer of a halogen between a metal centre and propagating radical, while metal-carbon bonds are reversibly formed in OMRP. ATRP and OMRP equilibria are able to operate simultaneously via the same iron(II) species when reactions are performed under ATRP conditions (alkyl halide initiator), though an OMRP-only regime can be accessed in the absence of alkyl halide (using an azo initiator). For reactions set-up under ATRP conditions, the degree of involvement of an OMRP mechanism is highly dependent on the metal centre, ligand environment and monomer involved. ${ }^{5 b, 7 a, b, d, 9,23}$ 
Atom transfer radical polymerisation (ATRP). All complexes were screened as mediators of the atom transfer radical polymerisation (ATRP) of styrene and methyl methacrylate (MMA), under the same reaction conditions we have previously described. ${ }^{7 d}$ The screening data obtained from the ATRP of styrene and MMA using our iron(II)- $\beta$-ketiminate complexes as mediators and (1-chloroethyl)benzene (1-PECl) as the initiator is provided in Tables S1 and S2 in the ESI. $\dagger$ All of the complexes are poor mediators of styrene ATRP, with broad dispersities $(D>1.66)$ and number average molecular weights $\left(M_{\mathrm{n}}\right)$ far in excess of the theoretically predicted values $\left(M_{\mathrm{n}, \mathrm{th}}\right)$ derived from percentage conversion. The data obtained from the ATRP of MMA under identical conditions to those used for styrene polymerisation suggests that almost all of the iron(II)- $\beta$-ketiminate complexes screened are poor mediators of MMA ATRP, with picolyl-tethered complexes $\mathbf{3} \mathbf{a}$ and $\mathbf{3 b}$ offering a moderate degree of control $(\theta=1.45$ and 1.41 respectively). In all cases however, molecular weights are in excess of theoretical values predicted using the initial concentration of the initiator. This suggests inefficient initiation, and the potential of rapid radical termination reactions. However, initiators which produce MMA-type primary radicals and which have an ATRP equilibrium constant at least the same as that of propagating MMA-type radicals (e.g. ECPA and EBPA) might be expected to lead to a more efficient initiation process than when using 1-PECl. Therefore, while initial screening in related systems showed no significant impact on the nature of initiator, further ATRP studies with the use of initiators like ECPA could be performed if ATRP mediation of MMA is needed. Also if the $\mathrm{Fe}-\mathrm{Cl}$ bonds are too strong, radical concentration would remain high, concomitantly increasing dispersity and molecular weight.

Organometallic mediated radical polymerisation (OMRP). Compared with (R)ATRP, the use of iron complexes as mediators of OMRP has received much less attention, with few examples of the use of iron(II) complexes in pure OMRP processes. ${ }^{5 a, c, 7 d, 23 a, 24}$ This is partially due to the oxygen sensitivity of many iron(II) complexes, which may preclude their handling under ambient laboratory conditions.

Given this paucity of literature on iron-mediated OMRP, it is not surprising that only a single report has described the polymerisation of either styrene or MMA under purely OMRP conditions (i.e. in the complete absence of halide). ${ }^{7 d}$ Table S3† presents the data obtained for the polymerisation of styrene under OMRP conditions using our range of iron(II) complexes and 1 equivalent of AIBN as the initiator. Most of the complexes tested exhibit little or no control over the OMRP of styrene, with the $D$ of these reactions being greater than 1.8. However, picolyl-containing complexes $3 \mathbf{a}$ and $4 \mathbf{4 a}$ display a moderate degree of control over the reactions, with $\oslash$ s of 1.58 and 1.61 being achieved. This represents a much higher degree of control under these conditions than we were able to achieve using our best performing iron(II) amine-bis(phenolate) complex, ${ }^{7 d}$ and may suggest improved carbon radical trapping by these systems. The presence of a picolyl donor and HMDS ligand appear important, since switching either the tethered donor (to a tertiary amine or ether) or the ancillary donor (to an alkoxide/phenoxide) reduces control significantly. However, in all cases the theoretical molecular weights are somewhat lower than the values obtained via GPC, indicating loss of a significant number of radicals before an OMRP equilibrium is established.

Based on our previous findings, ${ }^{7 d}$ we anticipated that control over the OMRP of MMA would be much easier to achieve (than styrene) given the apparent greater affinity of iron complexes for MMA-type radicals. Table 1 illustrates the screening data obtained for the OMRP of MMA under the same conditions as those used for styrene OMRP. It is evident that many of the complexes are reasonably efficient mediators of MMA OMRP, with $Đ$ s of $<1.53$ for all complexes tested. The picolyl-substituted complexes (3a, $\mathbf{4 a}, \mathbf{3 b}$ and $\mathbf{3 c}$ ) lead to significantly lower conversions, however, than the amine and ether-tethered complexes. Complex $3 \mathbf{c}$ specifically gave a very low conversion $(9 \%)$ to polymer, with minimal solid visible after attempted precipitation in acidified methanol. The top performing complex was $1 \mathrm{c}(\theta=1.33)$, where the electron-withdrawing terphenolate ligand can both sterically protect the iron centre and promote increased Lewis acidity and a stronger metal-carbon bond. Attempts were made to improve the performance of complex 1c (entry 7, Tables 1 and 2). It was observed that halving the number of equivalents of AIBN (entry 9, Table 2) led to a decrease in $D$ (to 1.23) and, as expected, a decrease in conversion. Since each molecule of AIBN generates two radicals upon thermal decomposition, at a ratio of $1: 1$ (AIBN:Fe) there are two radicals per iron(II) centre. This excess of radicals (with respect to iron(II)) should result in more termination at the early stages of the reaction. However, by halving the amount of AIBN (entry 9, Table 2), there is no longer an excess of radicals per iron(II) centre, which may help reduce termination reactions and thus improve dispersity. The use of the alternative radical initiators,

Table 1 MMA OMRP screening ${ }^{a}$

\begin{tabular}{|c|c|c|c|c|c|c|}
\hline Entry & Complex & $\begin{array}{l}\text { Conv. } \\
(\%)\end{array}$ & $\begin{array}{l}M_{\mathrm{n}, \mathrm{th}}[\mathrm{AIBN}] \\
(\mathrm{Da})\end{array}$ & $\begin{array}{l}M_{\mathrm{n}, \mathrm{th}}[\mathrm{Fe}] \\
(\mathrm{Da})\end{array}$ & $\begin{array}{l}M_{\mathrm{n}} \\
(\mathrm{Da})\end{array}$ & $Ð$ \\
\hline 1 & $1 a$ & 73 & 3654 & 7308 & 11764 & 1.47 \\
\hline 2 & $2 a$ & 69 & 3454 & 6908 & 11704 & 1.37 \\
\hline 3 & $3 \mathbf{a}$ & 13 & 651 & 1302 & 13862 & 1.49 \\
\hline 4 & $4 a$ & 22 & 1101 & 2202 & 11128 & 1.53 \\
\hline 5 & $1 b$ & 56 & 2803 & 5606 & 10229 & 1.45 \\
\hline 6 & $3 \mathbf{b}$ & 36 & 1802 & 3604 & 10123 & 1.41 \\
\hline 7 & $1 c$ & 54 & 2703 & 5406 & 10734 & 1.33 \\
\hline 8 & $3 c$ & 9 & 451 & 902 & & \\
\hline
\end{tabular}

${ }^{a}$ Conditions: $[\mathrm{MMA}]:\left[\mathrm{Fe}^{\mathrm{II}}\right]:[\mathrm{AIBN}]=100: 1.00: 1.00$, MMA $:$ toluene $=$ $1: 1(\mathrm{v} / \mathrm{v}), 110{ }^{\circ} \mathrm{C}, 1$ hour. Conversion determined by ${ }^{1} \mathrm{H}$ NMR spectroscopy. $M_{\mathrm{n} \text {,th }[\mathrm{AIBN}]}=[\mathrm{MMA}]_{\mathrm{o}} /\left(2 \times[\mathrm{AIBN}]_{0}\right) \times \mathrm{M}(\mathrm{MMA}) \times$ conversion. $M_{\mathrm{n}, \mathrm{th}[\mathrm{Fe}]}=[\mathrm{MMA}]_{\mathrm{o}} /[\mathrm{Fe}] \times \mathrm{M}(\mathrm{MMA}) \times$ conversion. ${ }^{b}$ Too little polymer obtained for GPC analysis. 
Table 2 Optimisation of MMA OMRP using complex $1 c^{a}$

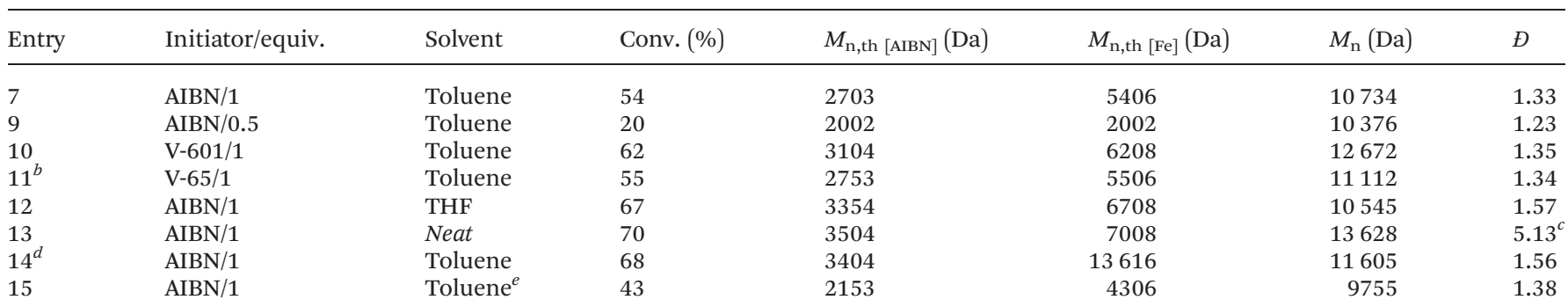

${ }^{a}$ Conditions: $[\mathrm{MMA}]:\left[\mathrm{Fe}^{\mathrm{II}}\right]:$ initiator] $=100: 1.00: \mathrm{X}, \mathrm{MMA}:$ solvent $=1: 1(\mathrm{v} / \mathrm{v}), 110{ }^{\circ} \mathrm{C}, 1$ hour. Conversion determined by ${ }^{1} \mathrm{H}$ NMR spectroscopy. $M_{\mathrm{n}, \text { th }[\mathrm{AIBN}]}=[\mathrm{MMA}]_{0} /\left(2 \times[\mathrm{AIBN}]_{0}\right) \times \mathrm{M}(\mathrm{MMA}) \times$ conversion. $M_{\mathrm{n}, \text { th }[\mathrm{Fe}]}=[\mathrm{MMA}]_{0} /[\mathrm{Fe}] \times \mathrm{M}(\mathrm{MMA}) \times$ conversion. ${ }^{b}$ Reaction performed for 2 hours at $90{ }^{\circ} \mathrm{C} .{ }^{c}$ Bimodal distribution. ${ }^{d} 0.5$ equivalents of $1 \mathrm{c} .{ }^{e} \mathrm{MMA}$ : toluene $=1: 2(\mathrm{v} / \mathrm{v})$.

V-601 (10 hour $\left.t_{1 / 2}=66^{\circ} \mathrm{C}\right)$, a non-nitrile initiator with a similar decomposition profile to AIBN or V-65 (10 hour $t_{1 / 2}=51{ }^{\circ} \mathrm{C}$ ), a lower temperature radical initiator, led to very similar results to those obtained with AIBN (entries 10 and 11, Table 2). Note that the reaction using V-65 was performed for 2 hours at a lower temperature $\left(90^{\circ} \mathrm{C}\right)$, since we anticipated a lower rate of propagation and thus slower conversion to polymer. At this lower temperature, it appears that trapping of the propagating radicals is as efficient and reversible as at the higher reaction temperature. Given the rapid rate of initiator decomposition at these temperatures, this should leave the decomposition of the soformed organometallic complex as the only source of radicals. Thus it is likely that the reaction proceeds via an RT-OMRP (reversible termination-OMRP) mechanism rather than a DT-OMRP mechanism (degenerative transfer-OMRP). The use of THF (entry 12) as solvent, or performing the reaction in the bulk (entry 13) both had deleterious on reaction control, raising $D$ to 1.57 and 5.13 respectively. These results together imply that minimal stabilisation of the metal centre occurs in the presence of coordinating solvent, and that in the absence of solvent (or in the presence of a relatively volatile solvent (THF)), propagation and bimolecular coupling of radical chains are rapid giving high conversions and broad $Ð$. However, doubling the volume of additional solvent (entry 15) had no further positive effect on control over the reaction.

As described previously, complex $3 \mathbf{c}$ gave an especially poor conversion to polymer, even with the use of an excess of radical initiator. We sought to examine the fate of complex 3c and thus, presumably, the reason for this low conversion by reacting it with MMA-type radicals, which can be generated by thermal decomposition of the azo initiator, V-601. The reaction was observed to darken over time, and an amount of black solid along with a small number of black crystals could be obtained via vapour diffusion of $n$-hexane in to the crude reaction mixture (Fig. 5). The molecular structure of the complex obtained $\left(\mathbf{3} \mathbf{c}^{\prime}\right)$ illustrates a monomeric iron(III) complex, bearing two terphenolate donors. Of particular note in this structure is the substitution of a picolyl $\mathrm{H}$ atom for a methyl isobutyrate group, the methyl isobutyrate being derived from the decomposition of V-601. While it is difficult to speculate on the origin of this complex without further experimental

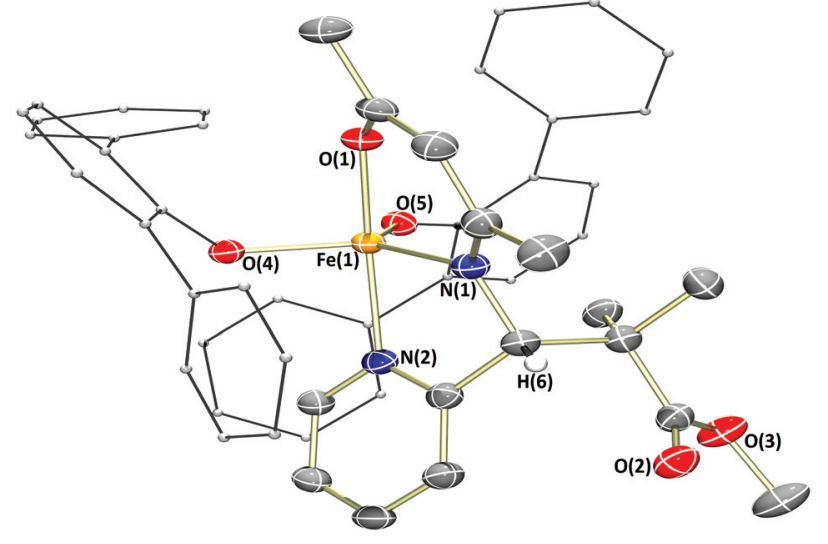

Fig. 5 Molecular structures of $3 c^{\prime}$ with ellipsoids set at the $50 \%$ probability level. Hydrogen atoms (except picolyl $\mathrm{H}$ atom) have been omitted for clarity. Terphenolate rings represented in ball and stick form for clarity. Selected bond lengths (Å): 3c' - Fe1-O1 1.9376(12), Fe1-O4 1.8995(12), Fe1-O5 1.8554(12), Fe1-N1 2.0856(15), Fe1-N2 2.1341(14).

corroboration, we suggest that it is likely formed via initial $\mathrm{H}$ atom abstraction by one equivalent of methyl isobutyrate radical, followed by radical-radical combination of the soformed $\beta$-ketiminate-derived radical with a further methyl isobutyrate radical. The addition of a further methyl isobutyrate group to the picolyl tether is likely precluded by steric factors. The loss of radicals via reaction with the ligand scaffold in this manner will certainly suppress productive polymerisation, hence accounting for the very low conversion obtained for complex 3c. This type of reactivity may account for the lower conversions obtained using the other complexes bearing picolyl tethers ( $c f$. entries 3, 4, 6 and 8, Table 1 ).

While the lower dispersities in most OMRP reactions described here imply some level of control over the radical polymerisation, the deviation from unity also suggests that termination reactions must be occurring. This is further supported by kinetic analysis of the OMRP of MMA mediated by complex 1a (see ESI $\dagger$ ), which shows that molecular weights top out at higher conversions. Thus, catalytic chain transfer events are kinetically competitive with propagation, as has been observed previously in $\alpha$-diimine iron systems. ${ }^{25}$ 


\section{Conclusions}

A series of donor-tethered tridentate $\beta$-ketiminate ligands have been synthesised and coordinated to iron(II) to afford fourcoordinate complexes bearing a coordinated bis(trimethylsilyl) amide group. Protonolysis of these complexes with either benzyl alcohol or 2,6-diphenylphenol led to the formation of dimeric iron(II) complexes. All of the complexes synthesised were examined as mediators of styrene and methyl methacrylate polymerisation under both ATRP, and OMRP conditions. While all complexes were generally very poor mediators of ATRP, Ds as low as 1.23 could be achieved in the OMRP of MMA. Furthermore, through crystallographic characterisation of a decomposition product, we provide evidence that the presence of reactive picolyl $\mathrm{H}$ atoms may have a detrimental effect on a complex's ability to act as an efficient mediator of CRP. Clear design principles to manage metal-halogen and metalcarbon bond strengths are emerging and continue to guide our design of iron-based catalysts in promoting controlled radical polymerisation and limiting chain transfer. As we understand the role of these complexes in controlling radical chemistry, we can consider applying them to other transformations. In particular, the application of these complexes (1a3c) as catalysts for small molecule transformations invoking radical chemistry is also an area of interest to our group, ${ }^{26}$ and will underpin future studies.

\section{Experimental}

\section{Materials and methods}

All experiments involving moisture- and air-sensitive compounds were performed under a nitrogen atmosphere using an MBraun LABmaster sp glovebox system equipped with a $-35{ }^{\circ} \mathrm{C}$ freezer and $\left[\mathrm{H}_{2} \mathrm{O}\right]$ and $\left[\mathrm{O}_{2}\right]$ analysers or using standard Schlenk techniques. Solvents used were obtained from a solvent purification system (Innovative Technologies) consisting of columns of alumina and copper catalyst and were further degassed by three freeze-pump-thaw cycles prior to use. Benzene- $d_{6}$ and THF- $d_{8}$ were dried by stirring over sodium/benzophenone, before being collected by distillation and degassed by three freeze-pump-thaw cycles. Chloroform$d_{1}$ was used as received. Styrene and methyl methacrylate (MMA) were dried by stirring over calcium hydride for a minimum of 24 hours, before being vacuum transferred and stored at $-35{ }^{\circ} \mathrm{C} .2,2^{\prime}$-Azobis(2-methylpropionitrile) (AIBN), V-601 (Wako) and V-65 (Wako) were recrystallised from DCM/ hexane, dried under vacuum and stored at $-35^{\circ} \mathrm{C}$. (1-Chloroethyl)benzene (1-PECl) and benzyl alcohol were dried by stirring over calcium hydride for a minimum of 24 hours, before being distilled. $\left[\mathrm{Fe}\left(\mathrm{N}\left(\mathrm{SiMe}_{3}\right)_{2}\right)_{2} \mathrm{THF}\right]$ was synthesised using a modified literature procedure. ${ }^{18}$ (4-Methoxypyridin-2-yl)methanamine was synthesised using a literature procedure. ${ }^{27}$ Following purification, all reagents described above were stored under an inert atmosphere. 2,6-Diphenylphenol, acetylacetone, $\mathrm{N}, \mathrm{N}$-dimethylethylenediamine, 2-picolylamine and tetrahydro- furfurylamine were all used as received. Gel permeation chromatography (GPC) was carried out in THF at a flow rate of $1 \mathrm{~mL} \min ^{-1}$ at $35{ }^{\circ} \mathrm{C}$ on a Malvern Instruments Viscotek 270 GPC Max triple detection system with $2 \times$ mixed bed styrene/ DVB columns $(300 \times 7.5 \mathrm{~mm})$. Absolute molar masses were obtained using $\mathrm{d} n / \mathrm{d} c$ values of 0.185 for poly(styrene $)^{28}$ and 0.088 for poly(methyl methacrylate). ${ }^{29}$ NMR spectra were obtained on either a $400 \mathrm{MHz}$ or $500 \mathrm{MHz}$ Bruker Avance III spectrometer. Solution magnetic moments were determined via NMR spectroscopy using Evans' method. ${ }^{30}$ Mass spectra were obtained on a Bruker Daltonics micro TOF instrument operating in the positive ion electrospray mode. Elemental analyses were performed by Stephen Boyer at London Metropolitan University.

\section{Synthetic procedures}

General protocol for synthesis of ligand precursors $\mathbf{L 1 H}-$ L4H. Equimolar amounts of acetylacetone and amine were dissolved in methanol, with the resulting solution being heated at reflux with stirring for 24 hours. After this time, the yellow solution obtained was cooled to ambient temperature and the volatiles removed in vacuo. The resulting yellow oil was takenup in to dichloromethane and the solution dried over $\mathrm{MgSO}_{4}$. The $\mathrm{MgSO}_{4}$ was then removed by filtration and the dichloromethane was removed in vacuo to give the crude product as a yellow oil. $\mathbf{L 1 H}$ and $\mathbf{L} \mathbf{2 H}$ were further purified and obtained as pale yellow oils by distillation under high vacuum. $\mathbf{L 3 H}$ and L4H were further purified and obtained as colourless crystalline solids by storage at $-30^{\circ} \mathrm{C}$ in a minimum of an equivolume solution of diethyl ether $/ n$-hexane.

Data for L4H. ${ }^{1} \mathrm{H}$ NMR (500 MHz, $\mathrm{CDCl}_{3}$ ) $\delta 11.21$ (br s, $1 \mathrm{H}$, $\mathrm{NH}), 8.36(\mathrm{~d}, J=5.7 \mathrm{~Hz}, 1 \mathrm{H}, \mathrm{py} H), 6.77$ (d, $J=2.4 \mathrm{~Hz}, 1 \mathrm{H}, \mathrm{py} H)$, $6.69(\mathrm{dd}, J=5.7,2.4 \mathrm{~Hz}, 1 \mathrm{H}, \mathrm{py} H), 5.06(\mathrm{~s}, 1 \mathrm{H}), 4.52$ (d, $J=$ $\left.6.5 \mathrm{~Hz}, 2 \mathrm{H}, \mathrm{NCH}_{2} \mathrm{Py}\right), 3.82\left(\mathrm{~s}, 3 \mathrm{H}, \mathrm{OCH}_{3}\right), 2.03\left(\mathrm{~s}, 3 \mathrm{H}, \mathrm{CCH}_{3}\right)$, $1.92(\mathrm{~s}, 3 \mathrm{H}, \mathrm{CCH}) \mathrm{ppm} .{ }^{13} \mathrm{C}\left\{{ }^{1} \mathrm{H}\right\}$ NMR (126 $\left.\mathrm{MHz}, \mathrm{CDCl}_{3}\right)$ $\delta$ 195.8, 166.8, 163.1, 159.8, 150.9, 108.5, 107.0, 96.4, 55.3, 48.7, 29.1, 19.1 ppm. HRMS $\left(\mathrm{ESI}^{+}\right): m / z 221.1296[\mathrm{M}+\mathrm{H}]^{+}$ calculated $[\mathrm{M}+\mathrm{H}]^{+}$221.1285. Characterisation data for $\mathbf{L 1 H},{ }^{10 a}$ $\mathbf{L} \mathbf{2} \mathbf{H}^{10 b}$ and $\mathbf{L} 3 \mathbf{H}^{31}$ was found to be in agreement with that reported in the literature.

Synthesis of $\left[\mathrm{Fe}(\mathrm{L1})\left(\mathrm{N}\left(\mathrm{SiMe}_{3}\right)_{2}\right)\right]$ (1a). To a solution of $\left[\mathrm{Fe}\left(\mathrm{N}\left(\mathrm{SiMe}_{3}\right)_{2}\right)_{2} \mathrm{THF}\right](200 \mathrm{mg}, 0.45 \mathrm{mmol})$ in $n$-hexane $(2 \mathrm{ml})$ was added a solution of $\mathbf{L 1 H}(75.9 \mathrm{mg}, 0.45 \mathrm{mmol})$ in $n$-hexane $(2 \mathrm{ml}$ ) with stirring. The resultant solution was stirred at room temperature for 30 minutes. After this time, the solution was placed in a freezer at $-35{ }^{\circ} \mathrm{C}$, inducing the crystallisation of the product as large, green blocks, which were collected and dried in vacuo (144 mg, $0.37 \mathrm{mmol}, 84 \%$ ). A single crystal suitable for X-ray diffraction analysis was selected from the bulk material. ${ }^{1} \mathrm{H}$ NMR (500 MHz, $\left.\mathrm{C}_{6} \mathrm{D}_{6}\right) \delta$ 160.30, 96.46, 85.63, $6.32,-19.48,-28.34,-57.41 \mathrm{ppm}$. $\mu_{\text {eff }}$ (Evans' method, $\mathrm{C}_{6} \mathrm{D}_{6}$ ) = $4.9 \mu_{\mathrm{B}}$. Analysis Calculated for $\mathrm{C}_{15} \mathrm{H}_{35} \mathrm{FeN}_{3} \mathrm{OSi}_{2}$ : C, 46.74; H, 9.15; N, 10.90. Found: C, 46.61; H, 9.20; N, 10.82.

Synthesis of $\left[\mathrm{Fe}(\mathrm{L} 2)\left(\mathbf{N}\left(\mathrm{SiMe}_{3}\right)_{2}\right)\right]$ (2a). To a solution of $\left[\mathrm{Fe}\left(\mathrm{N}\left(\mathrm{SiMe}_{3}\right)_{2}\right)_{2} \mathrm{THF}\right](400 \mathrm{mg}, 0.89 \mathrm{mmol})$ in $n$-hexane $(4 \mathrm{ml})$ was added a solution of $\mathbf{L} 2 \mathbf{H}(163 \mathrm{mg}, 0.89 \mathrm{mmol})$ in $n$-hexane 
(4 ml) with stirring. The resultant solution was stirred at room temperature for 30 minutes. After this time, the volatiles were removed in vacuo, yielding a green crystalline solid $(341 \mathrm{mg}$, $0.86 \mathrm{mmol}, 96 \%$ ). Single crystals suitable for X-ray diffraction analysis were obtained on cooling a saturated $n$-hexane solution of the product to $-35{ }^{\circ} \mathrm{C} .{ }^{1} \mathrm{H}$ NMR $\left(500 \mathrm{MHz}, \mathrm{C}_{6} \mathrm{D}_{6}\right)$ $\delta$ 69.51, 30.03, 21.59, 19.92, 16.09, 14.97, 12.20, 10.61, 4.44, $3.92,2.79,-3.90,-15.29,-23.47$ ppm. $\mu_{\text {eff }}$ (Evans' method, $\left.\mathrm{C}_{6} \mathrm{D}_{6}\right)=5.3 \mu_{\mathrm{B}}$. Analysis Calculated for $\mathrm{C}_{16} \mathrm{H}_{34} \mathrm{FeN}_{2} \mathrm{O}_{2} \mathrm{Si}_{2}: \mathrm{C}, 48.23$; H, 8.60; N, 7.03. Found: C, 48.17; H, 8.68; N, 6.91.

Synthesis of $\left[\mathrm{Fe}(\mathrm{L3})\left(\mathrm{N}\left(\mathrm{SiMe}_{3}\right)_{2}\right)\right]$ (3a). To a solution of $\left[\mathrm{Fe}\left(\mathrm{N}\left(\mathrm{SiMe}_{3}\right)_{2}\right)_{2} \mathrm{THF}\right](400 \mathrm{mg}, 0.89 \mathrm{mmol})$ in $n$-hexane $(3 \mathrm{ml})$ was added a solution of $\mathbf{L} 3 \mathbf{H}(170 \mathrm{mg}, 0.89 \mathrm{mmol})$ in $n$-hexane $(17 \mathrm{ml})$ with stirring. The resultant mixture was stirred vigorously at room temperature for 1 hour. After this time, the solution was placed in a freezer at $-35{ }^{\circ} \mathrm{C}$ to complete crystallisation of the product, which was obtained as green needles following filtration and drying in vacuo $(300 \mathrm{mg}$, $0.74 \mathrm{mmol}, 83 \%$ ). Single crystals suitable for X-ray diffraction analysis were obtained on cooling a saturated $n$-hexane solution of the product to $-35{ }^{\circ} \mathrm{C}$. ${ }^{1} \mathrm{H}$ NMR $\left(500 \mathrm{MHz}, \mathrm{THF}_{8}\right.$ ) $\delta$ 166.17, 89.42, 58.34, 56.52, 9.22, -6.61, -9.85, -13.48, -37.25 ppm. $\mu_{\text {eff }}$ (Evans' method, $\mathrm{C}_{6} \mathrm{D}_{6}$ ) $=5.0 \mu_{\mathrm{B}}$. Analysis Calculated for $\mathrm{C}_{17} \mathrm{H}_{31} \mathrm{FeN}_{3} \mathrm{OSi}_{2}$ : C, 50.36; H, 7.71; N, 10.36. Found: C, 50.12; H, 7.52; N, 10.17.

Synthesis of $\left[\mathrm{Fe}(\mathrm{L4})\left(\mathrm{N}\left(\mathrm{SiMe}_{3}\right)_{2}\right)\right]$ (4a). To a solution of $\left[\mathrm{Fe}\left(\mathrm{N}\left(\mathrm{SiMe}_{3}\right)_{2}\right)_{2} \mathrm{THF}\right](200 \mathrm{mg}, 0.45 \mathrm{mmol})$ in toluene $(5 \mathrm{ml})$ was added a solution of $\mathbf{L 4 H}(98.2 \mathrm{mg}, 0.45 \mathrm{mmol})$ in toluene $(5 \mathrm{ml})$ with stirring. The resultant solution was stirred at room temperature for 1 hour. After this time, the volatiles were removed in vacuo, yielding the crude product as a green oily solid. Dissolution of this in a minimum of $n$-hexane, followed by storage at $-35{ }^{\circ} \mathrm{C}$ overnight gave the pure product as green crystals (141 mg, $0.32 \mathrm{mmol}, 72 \%$ ). A single crystal suitable for $\mathrm{X}$-ray diffraction analysis was selected from the bulk material. ${ }^{1} \mathrm{H}$ NMR (500 MHz, $\left.\mathrm{C}_{6} \mathrm{D}_{6}\right) \delta 167.48,82.93,55.49,50.91,8.47$, $3.70,-5.61,-13.46,-39.60 \mathrm{ppm}$. $\mu_{\text {eff }}$ (Evans' method, $\mathrm{C}_{6} \mathrm{D}_{6}$ ) = $5.4 \mu_{\mathrm{B}}$. Analysis Calculated for $\mathrm{C}_{18} \mathrm{H}_{33} \mathrm{FeN}_{3} \mathrm{O}_{2} \mathrm{Si}_{2}$ : C, 49.64; H, 7.64; N, 9.65. Found: C, 49.43; H, 7.43; N, 9.46.

Synthesis of [Fe(L1)OBn] (1b). Complex 1a (101 mg, $0.26 \mathrm{mmol})$ was taken-up in $n$-hexane $(4 \mathrm{ml})$. To this was added an $n$-hexane $(2 \mathrm{ml})$ solution of benzyl alcohol $(32.4 \mathrm{mg}$, $0.30 \mathrm{mmol}$ ) with stirring. The resultant mixture was stirred at room temperature for 30 minutes, during which time an orange crystalline solid formed. After this time, the reaction mixture was placed in a freezer at $-35^{\circ} \mathrm{C}$ for 18 hours to complete crystallisation of the product. The resulting orange crystalline solid was collected and dried in vacuo $(74.5 \mathrm{mg}$, $0.22 \mathrm{mmol}, 86 \%$ ). Single crystals suitable for X-ray diffraction analysis were obtained on cooling of a saturated solution of the compound in $n$-hexane at reflux. ${ }^{1} \mathrm{H}$ NMR $\left(500 \mathrm{MHz}, \mathrm{C}_{6} \mathrm{D}_{6}\right)$ $\delta$ 136.96, 119.92, 106.46, 67.36, 41.35, 16.22, 8.76, 3.31, 0.49, $-1.45,-2.59,-3.07,-4.15,-5.10,-5.53,-13.29,-23.32$, $-27.94,-30.86,-33.45,-42.26$ ppm. $\mu_{\text {eff }}$ (Evans' method, $\left.\mathrm{C}_{6} \mathrm{D}_{6}\right)=5.4 \mu_{\mathrm{B}}$. Analysis Calculated for $\mathrm{C}_{16} \mathrm{H}_{24} \mathrm{FeN}_{2} \mathrm{O}_{2}$ : C, 57.85; H, 7.28; N, 8.43. Found: C, 58.02; H, 7.13; N, 8.59.
Synthesis of [Fe(L3)OBn] (3b). Complex 3a (100 mg, $0.25 \mathrm{mmol})$ was taken-up in $n$-hexane $(5 \mathrm{ml})$. To this was added an $n$-hexane $(2 \mathrm{ml})$ solution of benzyl alcohol $(26.7 \mathrm{mg}$, $0.25 \mathrm{mmol}$ ) with stirring. On addition of benzyl alcohol, the reaction mixture immediately changed colour (to red), and a large amount of red precipitate formed. The resultant suspension was stirred vigorously at room temperature for 1 hour. The red solid was collected by filtration and was dried in vacuo (83.1 mg, $0.24 \mathrm{mmol}, 96 \%$ ). $\mu_{\text {eff }}$ (Evans' method, THF-d ${ }_{8}$ ) = $5.2 \mu_{\mathrm{B}}$. Analysis Calculated for $\mathrm{C}_{18} \mathrm{H}_{20} \mathrm{FeN}_{2} \mathrm{O}_{2}$ : C, 61.38; H, 5.72; N, 7.95. Found: C, 61.29; H, 5.61; N, 7.88. ${ }^{32}$

Synthesis of [Fe(L1)OTer] (1c). Complex 1a (112 mg, $0.29 \mathrm{mmol}$ ) was taken-up in toluene $(2 \mathrm{ml})$. To this was added a toluene $(2 \mathrm{ml})$ solution of 2,6-diphenylphenol $(71.6 \mathrm{mg}$, $0.29 \mathrm{mmol}$ ) with stirring. The resultant mixture was stirred at room temperature for 1 hour. After this time the volatiles were removed in vacuo. The resultant residue was recrystallised from toluene/ $n$-hexane, giving the pure product as a yellow-orange, microcrystalline powder (99.1 mg, $0.21 \mathrm{mmol}$, 73\%). Single crystals suitable for X-ray diffraction analysis were obtained on storage of a concentrated solution of the compound in toluene/ $n$-hexane at $-35{ }^{\circ} \mathrm{C} .{ }^{1} \mathrm{H}$ NMR $\left(500 \mathrm{MHz}, \mathrm{THF}-\mathrm{d}_{8}\right)$ $\delta 71.77,68.69,36.83,21.33,6.51,3.74,-1.15,-8.51,-17.29$, $-22.44,-30.07$ ppm. $\mu_{\text {eff }}$ (Evans' method, $\left.\mathrm{C}_{6} \mathrm{D}_{6}\right)=5.1 \mu_{\mathrm{B}}$. Analysis Calculated for $\mathrm{C}_{27} \mathrm{H}_{30} \mathrm{FeN}_{2} \mathrm{O}_{2}$ : C, 68.94; H, 6.43; N, 5.96. Found: C, 69.06; H, 6.56; N, 6.01.

Synthesis of [Fe(L3)OTer] (3c). A solution of complex 3a (80.0 $\mathrm{mg}, \quad 0.20 \mathrm{mmol}$ ) and 2,6-diphenylphenol (48.6 mg, $0.20 \mathrm{mmol})$ in toluene $(2 \mathrm{ml})$ was stirred at room temperature for 2 hours, during which time, a small amount of orange crystalline powder had formed. After this time, $n$-hexane $(15 \mathrm{ml})$ was added with stirring, and the resultant orange microcrystalline solid was collected by filtration, washed with $n$-hexane (3 ml) and dried in vacuo (70.8 $\mathrm{mg}, 0.14 \mathrm{mmol}, 73 \%)$. Single crystals suitable for X-ray diffraction analysis were obtained on storage of a concentrated solution of the compound in toluene/ $n$-hexane at $-35{ }^{\circ} \mathrm{C} .{ }^{1} \mathrm{H}$ NMR $\left(500 \mathrm{MHz}, \mathrm{THF}-\mathrm{d}_{8}\right)$ $\delta 52.17,51.31,35.42,29.53,24.05,21.63,5.96,-1.91,-12.22$, -21.80, -41.07. $\mu_{\text {eff }}$ (Evans' method, $\mathrm{C}_{6} \mathrm{D}_{6}$ ) $=4.8 \mu_{\mathrm{B}} \cdot{ }^{33}$ Analysis Calculated for $\mathrm{C}_{29} \mathrm{H}_{26} \mathrm{FeN}_{2} \mathrm{O}_{2}$ : C, 71.03; H, 5.34; N, 5.71. Found: C, 71.16; H, 5.40; N, 5.68.

Synthesis of $3 \mathbf{c}^{\prime}$. A solution of complex $3 \mathbf{c}(21.3 \mathrm{mg})$ and $\mathrm{V}-601(30.0 \mathrm{mg})$ in toluene $(1 \mathrm{ml})$ was heated with stirring at $90{ }^{\circ} \mathrm{C}$ for 2 hours. After this time, the mixture was cooled and $n$-hexane was allowed to diffuse in to the crude reaction mixture at ambient temperature, producing a black solid and a number of black crystals.

\section{CRP procedures}

General procedure for ATRP of styrene or MMA. In a glovebox, a small ampoule was charged with iron(II) complex (24.0 $\mu \mathrm{mol})$, monomer $(2.40 \mathrm{mmol})$ and toluene (toluene: monomer, $1: 1, \mathrm{v} / \mathrm{v})$. To this was added 1-PECl $(24.0 \mu \mathrm{mol})$ by microsyringe. The ampoule was brought out of the glovebox and heated at $120{ }^{\circ} \mathrm{C}$ for 1 hour with a stir-rate of $500 \mathrm{rpm}$. After this time, the ampoule was cooled rapidly to ambient 
temperature, and an aliquot removed for analysis by ${ }^{1} \mathrm{H}$ NMR spectroscopy to determine monomer conversion. The remainder of the reaction mixture was dissolved in a small volume of THF ( $c a .2 \mathrm{ml}$ ), and the polymer precipitated by addition of the THF solution to acidified methanol $\left(\mathrm{MeOH}: \mathrm{HCl}_{(\mathrm{aq})}\right.$, ca. $75 \mathrm{ml}: 1 \mathrm{ml}$ ). The polymer was collected by filtration and dried in vacuo.

General procedure for OMRP of styrene or MMA. In a glovebox, a small ampoule was charged with iron(II) complex (24.0 $\mu \mathrm{mol})$, monomer $(2.40 \mathrm{mmol})$, toluene (toluene: monomer, $1: 1, \mathrm{v} / \mathrm{v})$ and AIBN $(24.0 \mu \mathrm{mol})$. The ampoule was brought out of the glovebox and heated at $110{ }^{\circ} \mathrm{C}$ for 1 hour with a stir-rate of $500 \mathrm{rpm}$. After this time, the ampoule was cooled rapidly to ambient temperature, and an aliquot removed for analysis by ${ }^{1} \mathrm{H}$ NMR spectroscopy to determine monomer conversion. The remainder of the reaction mixture was taken-up in a small volume of THF ( $c a .2 \mathrm{ml}$ ), and the polymer precipitated by addition of the THF solution to acidified methanol $\left(\mathrm{MeOH}: \mathrm{HCl}_{(\mathrm{aq})}\right.$, ca. $\left.75 \mathrm{ml}: 1 \mathrm{ml}\right)$. The polymer was collected by filtration and dried in vacuo.

\section{Crystallography}

X-Ray diffraction data was collected on an Agilent SuperNova diffractometer fitted with an Atlas CCD detector with Mo-K $\mathrm{K}_{\alpha}$ radiation $(\lambda=0.7107 \AA)$ or $\mathrm{Cu}-\mathrm{K}_{\alpha}$ radiation $(\lambda=1.5418 \AA)$. Crystals were mounted under paratone on MiTeGen loops. The structures were solved by direct methods using SHELXS or SHELXT interfaced through Olex 2 and refined by full-matrix least-squares on $F^{2}$ using SHELXL, interfaced through Olex2. ${ }^{34}$ Molecular graphics for all structures were generated using POV-RAY, POVLabel and Ortep.

\section{Acknowledgements}

M. P. S. and B. R. M. L. gratefully acknowledge support from the EPSRC (EP/M000842/1), a Marie Curie Career Integration Grant (FP7-PEOPLE-2013-CIG-618372) and the University of Edinburgh for financial support. We thank Dr Gary Nichol for collection of the X-ray diffraction data. We also thank Wako Chemicals $\mathrm{GmbH}$ for providing us with samples of the initiators V-601 and V-65, and Synthomer for useful discussions.

\section{Notes and references}

1 (a) I. Bauer and H.-J. Knölker, Chem. Rev., 2015, 115, 31703387; (b) I. Bauer and H.-J. Knölker, in Iron Catalysis in Organic Chemistry, Wiley-VCH Verlag GmbH \& Co. KGaA, 2008, pp. 1-27; (c) C. Bolm, J. Legros, J. Le Paih and L. Zani, Chem. Rev., 2004, 104, 6217-6254; (d) J. Gui, C.-M. Pan, Y. Jin, T. Qin, J. C. Lo, B. J. Lee, S. H. Spergel, M. E. Mertzman, W. J. Pitts, T. E. La Cruz, M. A. Schmidt, N. Darvatkar, S. R. Natarajan and P. S. Baran, Science, 2015, 348, 886-891; (e) J. M. Hoyt, V. A. Schmidt, A. M. Tondreau and P. J. Chirik, Science, 2015, 349, 960-963; (f) R. Pony Yu, D. Hesk, N. Rivera, I. Pelczer and P. J. Chirik, Nature, 2016, 529, 195-199; $(g)$ X. Jia and Z. Huang, Nat. Chem., 2016, 8, 157-161; (h) A. Sharma and J. F. Hartwig, Nature, 2015, 517, 600-604.

2 (a) J.-S. Wang and K. Matyjaszewski, J. Am. Chem. Soc., 1995, 117, 5614-5615; (b) J.-S. Wang and K. Matyjaszewski, Macromolecules, 1995, 28, 7901-7910.

3 (a) M. Kato, M. Kamigaito, M. Sawamoto and T. Higashimura, Macromolecules, 1995, 28, 1721-1723; (b) T. Ando, M. Kato, M. Kamigaito and M. Sawamoto, Macromolecules, 1996, 29, 1070-1072.

4 (a) T. Ando, M. Kamigaito and M. Sawamoto, Macromolecules, 1997, 30, 4507-4510; (b) K. Matyjaszewski, M. Wei, J. Xia and N. E. McDermott, Macromolecules, 1997, 30, 8161-8164; (c) Y. Kotani, M. Kamigaito and M. Sawamoto, Macromolecules, 1999, 32, 6877-6880; (d) B. Göbelt and K. Matyjaszewski, Macromol. Chem. Phys., 2000, 201, 1619-1624; (e) J. Louie and R. H. Grubbs, Chem. Commun., 2000, 1479-1480; (f) M. Teodorescu, S. G. Gaynor and K. Matyjaszewski, Macromolecules, 2000, 33, 23352339; ( $g$ ) G. Moineau, P. Dubois, R. Jérôme, T. Senninger and P. Teyssié, Macromolecules, 1998, 31, 545-547; (h) J. Xia, H.-j. Paik and K. Matyjaszewski, Macromolecules, 1999, 32, 8310-8314.

5 (a) Z. Xue, D. He and X. Xie, Polym. Chem., 2015, 6, 16601687; (b) B. R. M. Lake and M. P. Shaver, in Controlled Radical Polymerization: Mechanisms, American Chemical Society, 2015, vol. 1187, ch. 17, pp. 311-326; (c) R. Poli, L. E. N. Allan and M. P. Shaver, Prog. Polym. Sci., 2014, 39, 1827-1845.

6 (a) L. E. N. Allan, J. P. MacDonald, A. M. Reckling, C. M. Kozak and M. P. Shaver, Macromol. Rapid Commun., 2012, 33, 414-418; (b) L. E. N. Allan, J. P. MacDonald, G. S. Nichol and M. P. Shaver, Macromolecules, 2014, 47, 1249-1257.

7 (a) R. Poli and M. P. Shaver, Inorg. Chem., 2014, 53, 75807590; (b) H. Schroeder and M. Buback, Macromolecules, 2015, 48, 6108-6113; (c) H. Schroeder, M. Buback and M. P. Shaver, Macromolecules, 2015, 48, 6114-6120; (d) H. Schroeder, B. R. M. Lake, S. Demeshko, M. P. Shaver and M. Buback, Macromolecules, 2015, 48, 4329-4338.

8 J.-I. Lee, T.-Y. Lee, L.-C. Chang, C.-Y. Lin, H. M. Lee, L. Hung, A. Datta and J.-H. Huang, J. Mol. Struct., 2009, 929, 207-212.

9 R. Poli, Chem. - Eur. J., 2015, 21, 6988-7001.

10 (a) S. Gulli, J.-C. Daran and R. Poli, Eur. J. Inorg. Chem., 2011, 2011, 1666-1672; (b) H.-C. Tseng, M. Y. Chiang, W.-Y. Lu, Y.-J. Chen, C.-J. Lian, Y.-H. Chen, H.-Y. Tsai, Y.-C. Lai and H.-Y. Chen, Dalton Trans., 2015, 44, 11763-11773; (c) Y. Yamaguchi, H. Ando, M. Nagaya, H. Hinago, T. Ito and M. Asami, Chem. Lett., 2011, 40, 983-985.

11 D. M. Granum, P. J. Riedel, J. A. Crawford, T. K. Mahle, C. M. Wyss, A. K. Begej, N. Arulsamy, B. S. Pierce and M. P. Mehn, Dalton Trans., 2011, 40, 5881-5890. 
12 (a) S. J. J. Titinchi, G. Von Willingh, H. S. Abbo and R. Prasad, Catal. Sci. Technol., 2015, 5, 325-338; (b) A. Ray, G. Pilet, C. J. Gómez-García and S. Mitra, Polyhedron, 2009, 28, 511-520.

13 C. Scheiper, D. Dittrich, C. Wölper, D. Bläser, J. Roll and S. Schulz, Eur. J. Inorg. Chem., 2014, 2014, 2230-2240.

14 T. Akashi, J. Nakazawa and S. Hikichi, J. Mol. Catal. A: Chem., 2013, 371, 42-47.

15 L. Yang, D. R. Powell and R. P. Houser, Dalton Trans., 2007, 955-964.

16 (a) J. Cirera, P. Alemany and S. Alvarez, Chem. - Eur. J., 2004, 10, 190-207; (b) J. Cirera, E. Ruiz and S. Alvarez, Inorg. Chem., 2008, 47, 2871-2889.

17 A. F. Lugo and A. F. Richards, Inorg. Chim. Acta, 2010, 363, 2104-2112.

18 M. M. Olmstead, P. P. Power and S. C. Shoner, Inorg. Chem., 1991, 30, 2547-2551.

19 (a) S. A. Sulway, D. Collison, J. J. W. McDouall, F. Tuna and R. A. Layfield, Inorg. Chem., 2011, 50, 2521-2526; (b) G. Jin, L. Vendier, Y. Coppel, S. Sabo-Etienne and S. Bontemps, Dalton Trans., 2015, 44, 7500-7505; (c) B. A. Frazier, P. T. Wolczanski, E. B. Lobkovsky and T. R. Cundari, J. Am. Chem. Soc., 2009, 131, 3428-3429; (d) B. A. Frazier, V. A. Williams, P. T. Wolczanski, S. C. Bart, K. Meyer, T. R. Cundari and E. B. Lobkovsky, Inorg. Chem., 2013, 52, 3295-3312.

20 (a) D. J. Darensbourg, C. G. Ortiz and D. R. Billodeaux, Inorg. Chim. Acta, 2004, 357, 2143-2149; (b) P. Zhao, H. Lei, C. Ni, J.-D. Guo, S. Kamali, J. C. Fettinger, F. Grandjean, G. J. Long, S. Nagase and P. P. Power, Inorg. Chem., 2015, 54, 8914-8922; (c) J. S. Figueroa, J. G. Melnick and G. Parkin, Inorg. Chem., 2006, 45, 7056-7058; (d) T. J. Boyle, L. A. M. Ottley, C. A. Apblett, C. A. Stewart, S. M. Hoppe, K. L. Hawthorne and M. A. Rodriguez, Inorg. Chem., 2011, 50, 6174-6182; (e) C. Ni and P. P. Power, Chem. Commun., 2009, 5543-5545.

21 (a) E. M. Townsend, R. R. Schrock and A. H. Hoveyda, J. Am. Chem. Soc., 2012, 134, 11334-11337; (b) R. R. Schrock, A. J. Jiang, S. C. Marinescu, J. H. Simpson and P. Müller, Organometallics, 2010, 29, 5241-5251; (c) J. McKinven, G. S. Nichol and P. L. Arnold, Dalton Trans., 2014, 43, 17416-17421.

22 (a) F. di Lena and K. Matyjaszewski, Prog. Polym. Sci., 2010, 35, 959-1021; (b) R. Poli, Eur. J. Inorg. Chem., 2011, 2011, 1513-1530.

23 (a) L. E. N. Allan, M. R. Perry and M. P. Shaver, Prog. Polym. Sci., 2012, 37, 127-156; (b) R. Poli and M. P. Shaver, Chem. - Eur. J., 2014, 20, 17530-17540.
24 (a) J. Wang, J. Zhou, H. S. E. M. Sharif, D. He, Y. S. Ye, Z. Xue and X. Xie, RSC Adv., 2015, 5, 96345-96352; (b) Z. Xue and R. Poli, J. Polym. Sci., Part A: Polym. Chem., 2013, 51, 3494-3504.

25 (a) M. P. Shaver, L. E. N. Allan, H. S. Rzepa and V. C. Gibson, Angew. Chem., Int. Ed., 2006, 45, 1241-1244; (b) L. E. N. Allan, M. P. Shaver, A. J. P. White and V. C. Gibson, Inorg. Chem., 2007, 46, 8963-8970; (c) R. Poli and M. P. Shaver, Chem. - Eur. J., 2014, 20, 17530-17540.

26 (a) K. Zhu, M. P. Shaver and S. P. Thomas, Eur. J. Org. Chem., 2015, 2119-2123; (b) K. Zhu, M. P. Shaver and S. P. Thomas, Chem. - Asian J., 2016, 11, 977-980; (c) K. Zhu, M. P. Shaver and S. P. Thomas, Chem. Sci., 2016, 7, 3031-3035.

27 C. X. Zhang, S. Kaderli, M. Costas, E.-i. Kim, Y.-M. Neuhold, K. D. Karlin and A. D. Zuberbühler, Inorg. Chem., 2003, 42, 1807-1824.

28 S. Grcev, P. Schoenmakers and P. Iedema, Polymer, 2004, 45, 39-48.

29 K. Min, H. Gao, J. A. Yoon, W. Wu, T. Kowalewski and K. Matyjaszewski, Macromolecules, 2009, 42, 1597-1603.

30 D. F. Evans, J. Chem. Soc., 1959, 2003-2005.

31 V. A. Williams, P. T. Wolczanski, J. Sutter, K. Meyer, E. B. Lobkovsky and T. R. Cundari, Inorg. Chem., 2014, 53, 4459-4474.

32 Due to relatively poor solubility in deuterated solvents (THF- $\mathrm{d}_{8}, \mathrm{C}_{6} \mathrm{D}_{6}, \mathrm{CD}_{3} \mathrm{CN}$ ), we were unable to obtain a clear ${ }^{1} \mathrm{H}$ NMR spectrum with an acceptable signal-to-noise ratio. We believe the low quality of the spectra obtained also results from solution fluxionality.

33 The solution magnetic moment $\left(4.8 \mu_{\mathrm{B}}\right)$ determined for complex $3 \mathbf{c}$ is slightly lower than might be expected for a $\mathrm{d}^{6}$ high-spin complex. We suggest this is caused by lattice solvent, which is not accounted for in the solution magnetic moment calculation. Using the information obtained from the SQUEEZE routine in the crystallographic software, PLATON, it is calculated that there is electron density pertaining to approximately 2.5 molecules of solvent toluene (or hexane) per unit cell, which equates to approximately 0.6 molecules of toluene per dimer. If 0.6 molecules of toluene are included in the solution magnetic moment calculation, a value of $5.0 \mu_{\mathrm{B}}$ is obtained.

34 (a) O. V. Dolomanov, L. J. Bourhis, R. J. Gildea, J. A. K. Howard and H. Puschmann, J. Appl. Crystallogr., 2009, 42, 339-341; (b) G. Sheldrick, Acta Crystallogr., Sect. A: Fundam. Crystallogr., 2015, 71, 3-8; (c) G. Sheldrick, Acta Crystallogr., Sect. A: Fundam. Crystallogr., 2008, 64, 112-122. 